\title{
Coagulation Mechanisms during the Substitution of Inorganic Salts with Cationic Polymers to Increase the Sludge Value
}

\author{
Lelum Duminda Manamperuma, Harsha Chandima Ratnaweera \\ Department of Mathematical Sciences and Technology, Norwegian University of Life Sciences, Aas, Norway \\ Email: lelum.manamperuma@nmbu.no, harsha.ratnaweera@nmbu.no
}

Received 30 October 2015; accepted 22 December 2015; published 25 December 2015

Copyright (C) 2015 by authors and Scientific Research Publishing Inc.

This work is licensed under the Creative Commons Attribution International License (CC BY).

http://creativecommons.org/licenses/by/4.0/

(c) (i) Open Access

\begin{abstract}
Phosphorus in wastewater sludge is a valuable resource although coagulated sludge reported to give only $10 \%$ of plant availability of phosphates. Since all $\mathrm{Al}$ and Fe added as coagulants end up in sludge, the potential to substitute them with cationic coagulants was studied. During combined coagulation, substitution possibilities up to $44 \%$ were observed with low coagulant-to-particle ratio where the adsorption-charge neutralisation (ACN) anticipated being the predominant mechanism. Comparatively high coagulant-to-particle ratio preferred Sweep-floc mechanism giving $<20 \%$ substitution possibilities, though even lower values anticipated at higher phosphate removals. The cationic polymers' ability to compete with positively charged Al- and Fe-hydrolysis products was argued as the explanation for higher substitution possibilities during ACN mechanism. Substitutions can be enhanced with dual coagulation with intermediate sludge separation by avoiding competition between two coagulants.
\end{abstract}

\section{Keywords}

Organic Polymers, Inorganic Coagulants, Plant Availability of Phosphorus, Phosphorus Removal, Coagulation Mechanisms

\section{Introduction}

Over $70 \%$ of municipal wastewater in Norway is treated with a coagulation process [1] which annually consumes about 60,000 tons of inorganic coagulants consisting with $5 \%-18 \%$ of aluminium or iron [2]. These coagulants remove phosphorus very efficiently from wastewater thus solve a serious environmental problem. Norway has invested heavily in chemical precipitation as the main wastewater treatment process to manage eu- 
trophication of the lakes and rivers.

Wastewater sludge is no longer treated as a waste, but a resource. Over $70 \%$ of wastewater sludge in Norway is now used in agriculture benefiting the high content of nitrogen and phosphorus [1]. Phosphorus, which is a key element in mineral fertilizers, is anticipated to face a global deficit in the near future. The estimates show that the demand of phosphorus will exceed the supply by 2035 and the mineral phosphorous will disappear within the next 50 - 100 years [3]. The phosphorus prices has doubled since 2007, while there were periods with $800 \%$ price increase due to the scarcity in supplies [4].

However, there is a challenge with sludge from coagulation processes: Almost all aluminium and iron added during the coagulation process are transferred to the sludge. The plant availability of phosphorus (PAP) is significantly reported to be reduced in sludge from the chemical treatment plans; particularly where aluminium or iron salts is used as the precipitant. Krogstad in 2010 [5] reported that the PAP of sludge from wastewater treatment plants (WWTP) using aluminium and iron coagulants were about $10 \%$ and $24 \%$ respectively, compared to the sludge from biological treatment plants and mineral fertilizers [6].

Previous studies on PAP of coagulated sludge have reported that there is no significant difference of PAP in coagulated sludge and mineral fertilizers [7]-[11]. However, several recent studies have indicated that the higher the content of aluminium or iron in sludge, the lower the PAP [12]. Plant growth studies has documented that the content of aluminium or iron in sludge is inversely proportional to the phosphorus uptake by plants [13]. Thus, it is concluded that reduction of aluminium or iron in sludge will increase the PAP.

This paper presents results of attempts to reduce aluminium and iron content in sludge by substituting inorganic coagulants with organic coagulants, and discusses the limiting factors together with influence of coagulation mechanism.

\section{Material and Methods}

Part of the experiments was done in the laboratory with synthetic wastewaters enabling better replicability as well as the possibility for manipulating the composition of wastewater for various experimental conditions. We have chosen a synthetic wastewater composition representing common wastewater conditions and which have been successfully used in previous experiments [14]. For the current experiments wastewater with two variable phosphate contents and three particle contents were used. The properties of wastewaters are given in Table 1.

A part of experiments were carried out on domestic wastewater from three WWTPs in the Oslofjord area: Tønsberg WWTP, Sandefjord WWTP and Larvik WWTP. All three plants use coagulation as the main treatment process and deliver the sludge for agricultural purposes.

All used chemicals were pure chemicals from Merck and VWR Prolabo apart from humic acid, which was from Aldrich. Dry full-cream milk powder from Viking and potato starch from the Norwegian potato industries were used. Commercially available Aluminum Sulfate solution from Kemira (KEMIRA ALS) and 1 g/l solutions of commercially available polymer (FO-4240) from SNF Floerger were also used. The Kemira ALS solution is an inorganic salt $\left(\mathrm{Al}_{2}\left(\mathrm{SO}_{4}\right)_{3} \cdot 14 \mathrm{H}_{2} \mathrm{O}\right)$ with very low iron concentrated and commonly used in potable water and wastewater treatment applications and the FO-4240 is a high molecular weight and low charge density (cationicity 20\% mol) organic cationic polymer. Flocculant solution was vigorously homogenised with a magnetic stirrer until the flocculant was completely dissolved. Commercially available prepolymerised aluminium coagulant (KEMIRA PAX-XL-61) aqueous solution and Ferric Chloride Sulfate (KEMIRA PIX-318) from Kemira were used as coagulants with some experiments with domestic wastewater, enabling comparison with present full scale practices at WWTPs.

Table 1. Typical properties of two synthetic wastewater samples.

\begin{tabular}{cccc}
\hline & High phosphates & Medium phosphates & Low phosphates \\
\hline Turbidity (NTU) & 476 & 480 & 202 \\
Total Phosphorus (mg/L) & 9.9 & 7.53 & 499 \\
Suspended solids (mg/L) & 480 & 480 & 5.4 \\
Ortho Phosphate (mg/L) & 6.06 & 3.86 & 2.57 \\
\hline
\end{tabular}


Analysis were carried out using Hach Lange CLK349 and CLK350 rapid tests using Hach DR 3900 spectrophotometer and Hach LT 200 dry thermostat. Turbidity was measured by Merck Turbiquant 3000 IR while SS was measured using Norwegian standard methods.

Coagulation process with inorganic salts significantly depends on the $\mathrm{pH}$, which is reduced after coagulant addition due to the hydrolysis. The coagulation $\mathrm{pH}$ was held constant during the tests independently on the coagulant dosages by adjusting the raw water $\mathrm{pH}$ to result in the desired $\mathrm{pH}$, which was 7.5 in this series of experiments.

The coagulation experiments were carried using a Kemira Flocculator 2000 jar-test apparatus with six standard $1 \mathrm{~L}$ beakers. Samples were rapidly mixed at $400 \mathrm{rpm}$ for 30 seconds followed by slow mixing at $30 \mathrm{rpm}$ for $10 \mathrm{~min}$, and then sedimentation for $15 \mathrm{~min}$. At the beginning of the rapid mixing, Al- or Fe coagulants and cationic polymer (FO-4240) were added simultaneously to the jars. After sedimentation, $180 \mathrm{ml}$ of supernatant was taken as sample for further manual analysis. Inorganic coagulant dosage ranges suitable for wastewater types were varied while cationic polymer dosage range was kept constant between 0 to $7 \mathrm{mg} / \mathrm{l}$. Turbidity, $\mathrm{SS}, \mathrm{pH}$, total phosphates (Total-P) and ortho phosphates (Ortho-P) were measured in the supernatant. Randomly selected samples were analyzed in several replicates to control accuracy and to reduce the human errors.

\section{Results and Discussion}

We have carried out series of jar tests with 6 types of wastewater representing low-medium-high concentrations of particles and phosphates. Figure 1 shows the results for wastewater with high particle and phosphate contents.

Particle and phosphate removals in Figure 1(a) and Figure 1(b) are comparable to each other, and show that at lower aluminium dosages, the impact of cationic polymers are quite significant. The influence of cationic polymers diminishes with the increase of Al-dosage. For example, an $80 \%$ removal of SS or $50 \%$ removal of

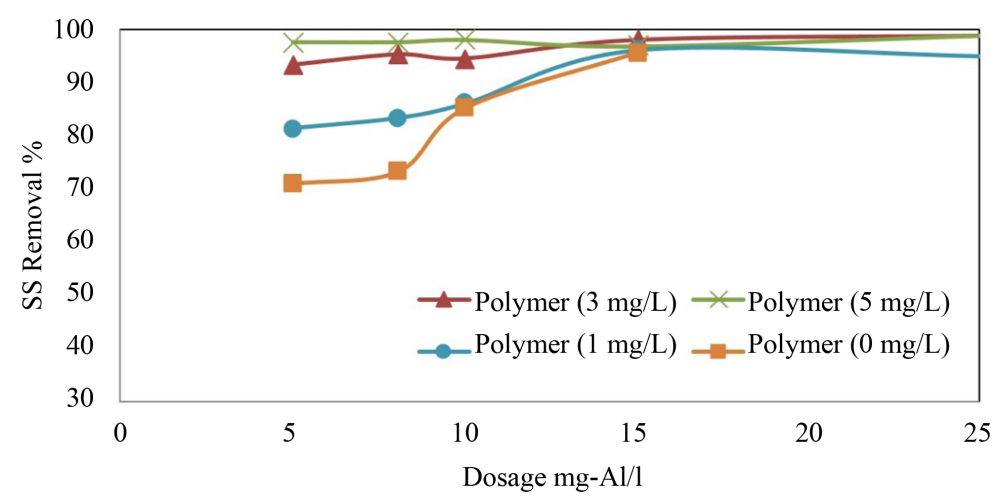

(a)

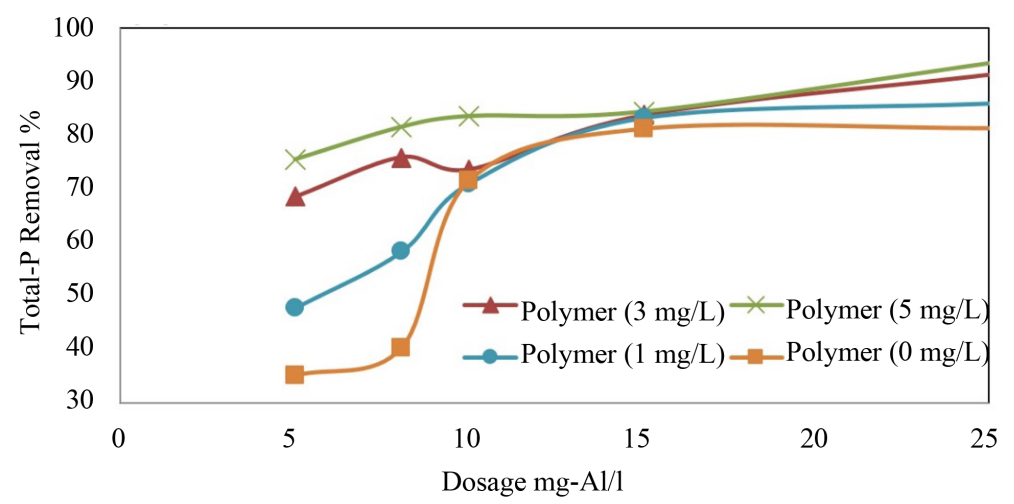

(b)

Figure 1. Influence of cationic polymers on SS (a) and phosphates (b) removal with aluminium sulphate, in wastewater with high SS and high phosphates. 
total-P was possible either with $9 \mathrm{mg}-\mathrm{Al} / \mathrm{l}$ or $5 \mathrm{mg}-\mathrm{Al} / \mathrm{l}$ combined with $1 \mathrm{mg} / \mathrm{l}$ of cationic polymers. To achieve $90 \%$ removal of SS or phosphates was possible with $13-15 \mathrm{mg}-\mathrm{Al} / \mathrm{l}$. However, the influence of cationic polymers was insignificant. We have repeated the results with two cationic polymers and the results were analogical.

Table 2 summarises the impact of cationic polymers on removal rates at 5 and $10 \mathrm{mg}-\mathrm{Al} / \mathrm{l}$ dosages. Molar ratio Al: $\mathrm{P}$ for the two dosages for six water types are also given for reference. The percentage values are given as the average of two cationic polymer types. Waters with high particle and phosphate contents had a significant influence (shaded values) by cationic polymers at lower treatment levels. With the reduction of particles, phosphates or increase of aluminium dosages (high coagulant-to-particle ratio), the differences became much less significant.

Figure 1 and Table 2 confirm that the impact of cationic polymers are largest when there are more particles and phosphates (low coagulant-to-particle ratio) as well as when the removal efficiencies are lower. These jar tests were done with simultaneous addition of $\mathrm{Al}$ coagulant and cationic polymer, thus a competition between the species of the two coagulants can be anticipated. When there are more particles and/or phosphates compared with the Aluminium, the dominance of adsorption-charge neutralisation (ACN) mechanism compared with Sweep-floc mechanisms can be anticipated. When the removal rates are lower, the amount of Al-species available is also lower thus the same conditions and results can be anticipated. When the ACN is the dominant mechanism, it is obvious that positively charged species from hydrolysis and cationic polymers have better opportunities to compete with each other under "similar" conditions; thus we can anticipate a higher substitution of inorganic coagulants by cationic polymers.

Similarly, when there is too much Al-species compared with the amount of particles (for e.g. water with low concentrations), the Sweep-floc mechanism is favoured and cationic polymers have less possibility to compete and substitute aluminium. The same situation occurs at higher removal rates under these tests, as the amount of Al-species versus particles or phosphates were much higher due to higher dosages, thus a similar situation occurs.

This concludes that for the extremely high SS and phosphate removal rates which are anticipated in Scandinavian WWTPs, it will be difficult to obtain significant reduction of aluminium and iron coagulants with cationic coagulants, when both coagulants are added simultaneously.

Nevertheless, if the two coagulants are added separately, it would be possible to achieve a significant substitution of aluminium with cationic polymers as there will be no competition between them. However the downside then will be the need for infrastructure and operational modifications to accommodate two coagulation stages.

Additional jar tests were carried out using domestic wastewater samples from three WWTPs, and the results are presented in Figure 2. The removal efficiencies of phosphates are depicted as a function of molar ratio between $\mathrm{Al}$ or $\mathrm{Fe}$ to $\mathrm{P}$. In these experiments we have used both aluminium and iron coagulants interchangeably but the results are presented in a comparable manner as molar ratios.

Table 2. Influence of cationic polymers on SS and Total-P removal efficiencies.

\begin{tabular}{|c|c|c|c|c|c|c|c|}
\hline \multicolumn{2}{|c|}{ Raw water } & \multicolumn{2}{|c|}{$\begin{array}{l}\text { Difference in SS } \\
\text { removal efficiency }\end{array}$} & \multicolumn{4}{|c|}{ Difference in total-P removal efficiencies } \\
\hline \multirow[t]{2}{*}{$\begin{array}{l}\text { Particle } \\
\text { content }\end{array}$} & \multirow[t]{2}{*}{$\begin{array}{c}\text { Phosphate } \\
\text { content }\end{array}$} & \multirow[t]{2}{*}{$\begin{array}{l}\text { With } 5 \\
\text { mg-Al/l }\end{array}$} & \multirow[t]{2}{*}{ With $10 \mathrm{mg}-\mathrm{Al} / \mathrm{l}$} & \multicolumn{2}{|c|}{ With 5 mg-Al/l } & \multicolumn{2}{|c|}{ With $10 \mathrm{mg}-\mathrm{Al} / \mathrm{l}$} \\
\hline & & & & Difference & $\begin{array}{l}\text { Al:P molar } \\
\quad \text { ratio }\end{array}$ & Difference & $\begin{array}{l}\text { Al:P molar } \\
\quad \text { ratio }\end{array}$ \\
\hline $\mathrm{L}$ & $\mathrm{L}$ & $4.5 \%$ & $7.0 \%$ & $12.0 \%$ & 1.1 & $9.5 \%$ & 2.1 \\
\hline M & $\mathrm{L}$ & $7.5 \%$ & $3.0 \%$ & $5.0 \%$ & 1.1 & $3.5 \%$ & 2.1 \\
\hline M & M & $5.0 \%$ & $6.0 \%$ & $6.5 \%$ & 0.8 & $8.0 \%$ & 1.5 \\
\hline $\mathrm{H}$ & $\mathrm{L}$ & $32.5 \%$ & $9.0 \%$ & $44.0 \%$ & 1.1 & $17.5 \%$ & 2.1 \\
\hline $\mathrm{H}$ & M & $25.0 \%$ & $8.0 \%$ & $40.0 \%$ & 0.8 & $11.0 \%$ & 1.5 \\
\hline $\mathrm{H}$ & $\mathrm{H}$ & $25.0 \%$ & $11.0 \%$ & $40.0 \%$ & 0.6 & $10.0 \%$ & 1.2 \\
\hline
\end{tabular}




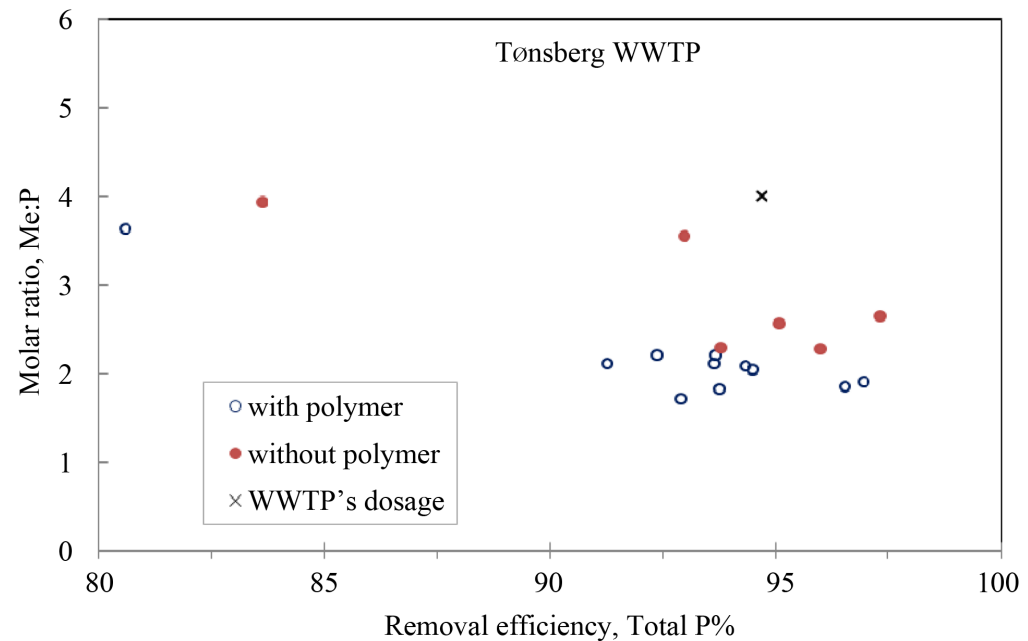

(a)

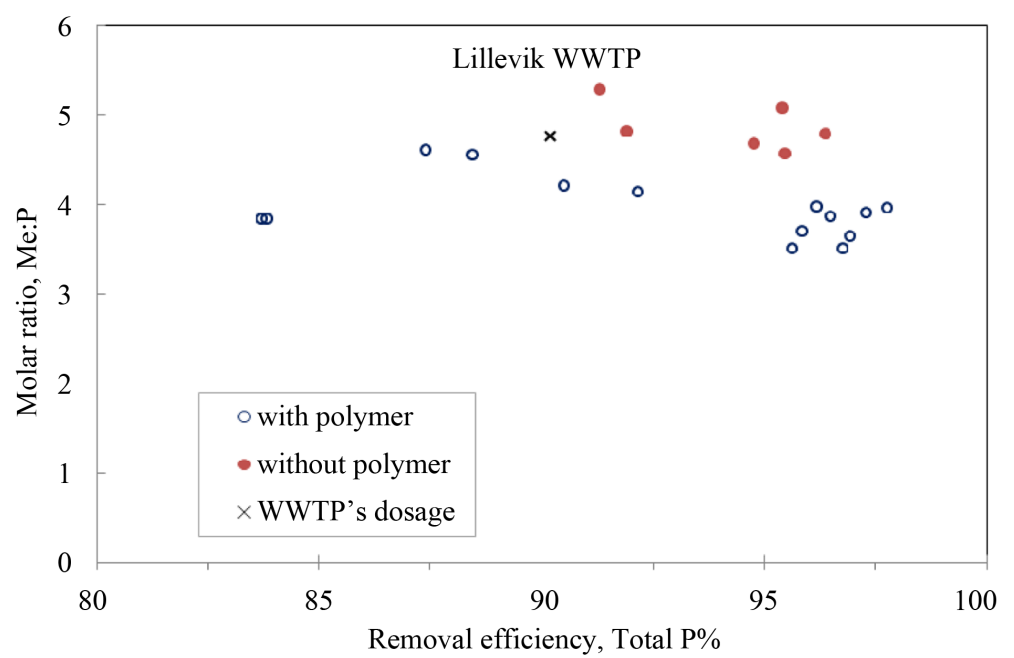

(b)

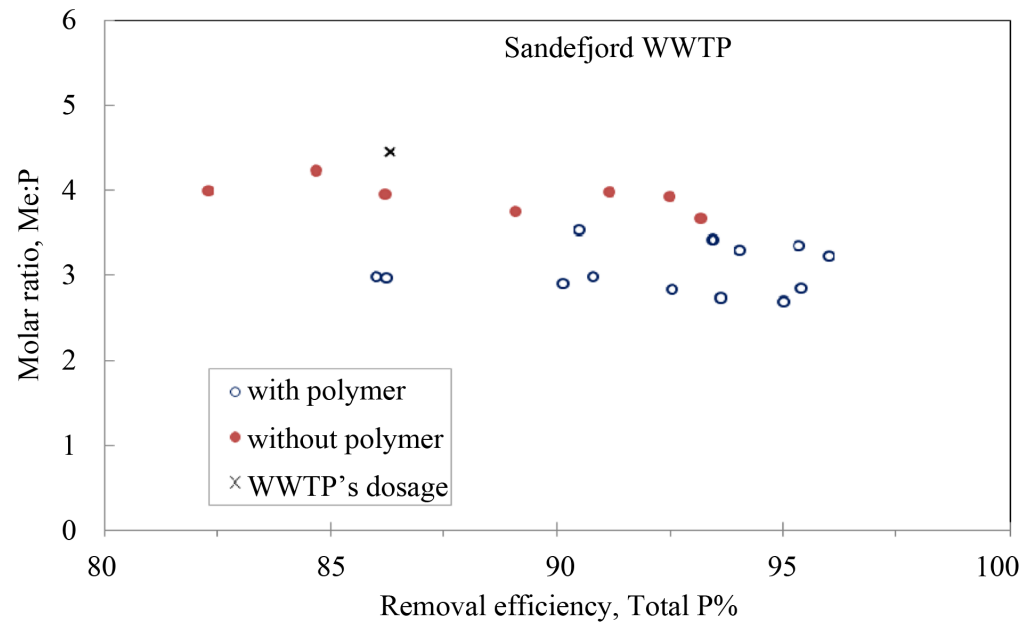

(c)

Figure 2. Removal efficiency of total-phosphates in wastewater from three WWTPs with and without cationic polymers. Top: Tønsberg WWTP, middle: Lillevik WWTP; bottom: Sandefjord WWTP. 
The filled circles in Figure 2 present the tests without polymers and empty circles refer to tests with cationic polymers. The single cross in each figure refers to the dosage which the WWTP was using at the sampling time. In all three WWTPs this ratio was between 4 and 5, which is quite high compared with the synthetic wastewater. A survey among average molar ratios used in ten Norwegian WWTPs revealed values between 2.0 - 5.0 with exception of one WWTP [15]. Compared with the theoretical requirement of 1 mole of aluminium per 1 mole of phosphates in aluminium phosphates, these values are much higher. On the other hand, the Al: P ratio will always be higher than 1 during the efficient phosphate removal by coagulation, as a part of aluminium end up in aluminium hydroxide making it unavailable for phosphate removal [16].

The task is to reduce as much as possible aluminium or iron dosage during coagulation as they will always end up in sludge. Figure 2 shows that $20 \%$ - 25\% of aluminium or iron coagulants could be substituted if the anticipated treatment efficiencies are $85 \%$ - 90\%. In most situations, the phosphorus removal requirement is well above $90 \%$, indicating that the substitution possibility will be lower than $25 \%$. Such a low substitution values may be not worth the trouble of having two coagulants, while dual coagulation with separate separation will give much better substituting opportunities.

Comparing the results from the synthetic wastewater, it becomes clear that better treatment efficiencies were possible with synthetic wastewater at lower coagulant dosages. This due is to considerably lower phosphate concentrations in domestic water during the specific sampling period. Considering the molar ratios and the discussion on coagulation mechanisms with synthetic wastewater, it is reasonable to assume that all tests presented in Figure 2 were running under the Sweep-floc condition, which will also make it difficult to increase the substitution by a cationic coagulant.

\section{Conclusions}

Studies show that the reduction of aluminium and iron is sludge will proportionally increase the plant availability of phosphorus in coagulated sludge. Since all aluminium and iron used in coagulation will go over to sludge substituting these ions with cationic polymers during coagulation would be a potential solution.

It is assumed that cationic polymers and positively charged inorganic species (Metal hydrolysis species) compete with each other in destabilisation of colloidal systems. It is anticipated that although the cationic polymers may compete successfully at low dosages per particles where adsorption-charge neutralisation mechanism is predominant. However at higher specific dosages, the ratio of aluminium to particles or phosphate is so high that the Sweep-floc mechanism will be preferred. During Sweep-floc mechanism, cationic polymers have insignificant possibilities to compete with inorganic hydrolysis species.

Very good substitution possibilities up to $44 \%$ were observed at lower treatment efficiencies or highly concentrated wastewater, where the amount of particles per unit coagulant is assumed to be low enough to make the adsorption-charge neutralisation as the predominant coagulation mechanism.

The substitution of up to $20 \%$ was possible during other situations. Since Scandinavian WWTPs require phosphate removals well above $90 \%$, the substitution possibilities with combined coagulation assumed to be low.

Cationic polymers have documented the possibility of removing particles-thus dual coagulation with intermediate sludge separation could be an interesting operational concept where the use and treatment efficiencies with organic coagulants could be maximised thus the need for inorganic coagulants will be minimised.

Further research to quantify the hypotheses is required and recommended.

\section{References}

[1] Berge, G. and Mellem, K.B. (2011) Kommunale avløp. Ressursinnsats, utslipp, rensning og slamdisponering 2010. Gebyrer 2011. Rapporter 46/2011, Statistisk sentralbyrå (Statistics Norway) (in Norwegian). http://www.ssb.no/emner/01/04/20/rapp_avlop/

[2] Brinchmann, A. (2012) Personlig kommunikasjon, Økning av fosfortilgjengelighet fra kjemiskslam ved kombinert bruk av organiske og uorganiske fellingsmidler Sluttrapport for BEDRIFTSPROSJEKT VRI-B Vannrenseteknologi 2012/956 (in Norwegian).

[3] Cordell, D., Drangert, J.O. and White, S. (2009) The Story of Phosphorus: Global Food Security and Food for Thought. Global Environmental Change, 19, 292-305. http://dx.doi.org/10.1016/j.gloenvcha.2008.10.009

[4] World Bank (2009) Commodity Price Data (Pink Sheet), Prospects for the Global Economy, World Bank. 
http://go.worldbank.org/5AT3JHWYU0

[5] Krogstad, T. (2010) Hvordan kan slam bli en bedre kilde for fosfor i matproduksjonen. VANN, 2, $251-256$ (in Norwegian).

[6] Krogstad, T., Sogn, T.A., Asdal, Å. and Sæbø, A. (2005) Influence of Chemically and Biologically Stabilized Sewage Sludge on Plant-Available Phosphorous in Soil. Ecological Engineering, 25, 51-60. http://dx.doi.org/10.1016/j.ecoleng.2005.02.009

[7] Coker, E.G. and Carlton-Smith, C.H. (1986) Phosphorus in Sewage Sludges as a Fertilizer. Waste Management \& Research, 4, 303-319. http://dx.doi.org/10.1177/0734242X8600400136

[8] Gestring, W.D. and Jarrell, W.M. (1982) Plant Availability of Phosphorus and Heavy Metals in Soils Amended with Chemically Treated Sewage Sludge. Journal of Environmental Quality, 11, 669-675. http://dx.doi.org/10.2134/jeq1982.00472425001100040022x

[9] Mengel, K. and Kirkby, E.A. (1982) Principles of Plant Nutrition (Intl. Potash Inst, Bern, Switzerland). Menge 1446 Principles of Plant Nutrition, 446.

[10] Bramryd, T. (2002) Impact of Sewage Sludge Application on the Long-Term Nutrient Balance in Acid Soils of Scots Pine (Pinus sylvestris, L.) Forests. Water, Air, and Soil Pollution, 140, 381-399. http://dx.doi.org/10.1023/A:1020142311652

[11] Watanabe, Y., Tadano, T., Hasegawa, T., Shimanuki, Y. and Ødegaard, H. (2000). Phosphorous Recycling from Pre-Coagulated Wastewater Sludge. In: Chemical Water and Wastewater Treatment VI, Springer Berlin Heidelberg, 359-371. http://dx.doi.org/10.1007/978-3-642-59791-6_33

[12] Bøen, A. (2010) Fosfor i avløpsslam-Fraksjonering og plantetilgjengelighet.

[13] Øgaard, A.F. (2013) Plantetilgjengelig fosfor i avløpsslam. Bioforsk Rapport. Vol. 8 Nr. 34 (in Norwegian).

[14] Fettig, J., Ratnaweera, H.C. and Ødegaard, H. (1990) Simultaneous Phosphate Precipitation and Particle Destabilization Using Aluminium Coagulants of Different Basicity. In: Chemical Water and Wastewater Treatment, Springer Berlin Heidelberg, 221-242. http://dx.doi.org/10.1007/978-3-642-76093-8 15

[15] Ratnaweera, H. (2013) Phosphorus Recovery from Wastewater-Should We Rebuild Our Wastewater Treatment Plants? VANN, 4, 551-556 (in Norwegian).

[16] Ratnaweera, H. (1991) Influence of the Degree of Coagulant Prepolymerization on Wastewater Coagulation Mechanisms. Doctoral Dissertation, Ph.D. Thesis, Norwegian Institute of Technology. 